\title{
Multiscale Approach to the Study of the Electronic Properties of two Thiophene Curcuminoid Molecules
}

A. Etcheverry-Berríos, ${ }^{[\mathrm{a}]}$ I. Olavarría, ${ }^{[\mathrm{b}]}$ M. L. Perrin, ${ }^{[\mathrm{b}]}$ R. Díaz-Torres,${ }^{[\mathrm{c}]}$ D. Jullian, ${ }^{[\mathrm{a]}]}$ I. Ponce,${ }^{[\mathrm{d}]}$ J. H. Zagal, ${ }^{[\mathrm{d}]}$ J. Pavez,${ }^{[\mathrm{d}]}$ S. O. Vásquez,${ }^{[\mathrm{a}]}$ H. S. J. van der Zant, ${ }^{[b]}$ D. Dulić, ${ }^{*[\mathrm{e}]}$ N. Aliaga-Alcalde ${ }^{*[\mathrm{f}]}$ and M. Soler ${ }^{*[\mathrm{a}}$

[a] Departamento de Ciencia de los Materiales, Facultad de Ciencias Físicas y Matemáticas, Universidad de Chile, Beaucheff 851, Santiago (Chile)

[b] Kavli Institute of Nanoscience, Delft University of Technology, Lorentzweg 1, 2628

CJ Delft (The Netherlands)

[c] Departament de Química Inorgànica, Universitat de Barcelona-ICMAB (Institute of MaterialsScience of Barcelona)-CSIC, Diagonal 645, 08028 Barcelona (Spain)

[d] Facultad de Química y Biología, Universidad de Santiago de Chile, Av. Libertador Bernardo Ohiggins 3363, Estación Central, Santiago (Chile)

[e] Departamento de Física, Facultad de Ciencias Físicas y Matemáticas, Universidad de Chile, Av. Blanco 2008, Santiago (Chile)

[f] ICREA Researcher (Institució Catalana de Recerca i Estudis Avançats) at the ICMAB-CSIC , Campus de la Universitat Autònoma de Barcelona 08193, Bellaterra (Spain) 


\begin{abstract}
We studied the electronic and conductance properties of two thiophene-curcuminoid molecules, 2-thphCCM (1) and 3-thphCCM (2), where the only structural difference is the position of the sulfur atoms in the thiophene terminal groups. We used electrochemical techniques as well as UV-vis absorption studies to obtain the values of the HOMO-LUMO band gap energies, showing that molecule 1 has lower values than 2. Theoretical calculations show the same trend. Self-assembled monolayers (SAMs) of these molecules were studied using electrochemistry, showing that the interaction with gold reduces drastically the HOMO-LUMO gap in both molecules to almost the same value. Single-molecule conductance measurements show that molecule 2 has two different conductance values, whereas molecule 1 exhibits only one. Based on theoretical calculations we conclude that the lowest conductance value, similar in both molecules, corresponds to a van der waals interaction between the thiophene ring and the electrodes. The one order of magnitud higher conductance value for molecule 2 corresponds to a covalent interaction between the sulfur atoms and the gold electrodes.
\end{abstract}




\section{Introduction}

Molecular electronics is a field of nanoscience and nanotechnology that consists of studying single molecules, or nanoscale collections of single molecules, as electronic components at the molecular level. It focuses on the ability to tune the intrinsic properties of molecules ${ }^{1}$ for better device performance. During the last decade, a number of organic species and coordination compounds have been proposed and their electronic and charge transport properties have been studied in the context of singlemolecule based devices. ${ }^{2}$ Factors as the length, ${ }^{3}$ conjugation, ${ }^{4}$ conformation, ${ }^{5 a}$ or even changes in the planarity of the molecule ${ }^{5}$ and anchoring groups ${ }^{6}$ of the molecule under study, are crucial for achieving reliable electronic devices with desirable performance. ${ }^{7}$ In particular several studies have been centered on understanding the effect that different anchoring groups can have on the conductance in a single-molecule device, anchoring groups such as $\mathrm{HS},{ }^{3 \mathrm{~b}, 8 \mathrm{a}-\mathrm{d}} \mathrm{COOH},{ }^{8 \mathrm{a}, \mathrm{e}} \mathrm{NH}_{2},{ }^{3 \mathrm{~b}, 8} \mathrm{MeS},{ }^{3 \mathrm{c}, 8 \mathrm{f}} \mathrm{Me}_{2} \mathrm{P}^{8 \mathrm{a}} \mathrm{MeSe}^{3 \mathrm{c}}$ thiophene, ${ }^{3 \mathrm{c}}$ selenophene, $^{3 \mathrm{c}}$ tripodal anchors with pyridine-rings, ${ }^{9}$ pyridine, ${ }^{3 \mathrm{~b}, 8 \mathrm{~d}, \mathrm{e}}$ $\mathrm{CN},{ }^{3 \mathrm{~b}, 8 \mathrm{~d}, \mathrm{e}}$ benzo-hydrothiophene, ${ }^{3 \mathrm{~b}, 8 \mathrm{~d}} \quad \mathrm{SO}_{3}{ }^{-8 \mathrm{e}} \mathrm{OH},{ }^{8 \mathrm{e}}$ alkyne, ${ }^{8 \mathrm{c}, \mathrm{d}} \quad \mathrm{NO}_{2}{ }^{8 \mathrm{~d}}$ and benzothiophene. $^{8 \mathrm{~d}}$ Thus, establishing a relation between intrinsic molecular properties and device performance is a central task for developing reliable molecular electronic devices.

In this work we investigate the electrochemical and single-molecule charge transport properties of two thiophene-terminated curcuminoid (CCMoid) molecules, 2-thphCCM (1) and 3-thphCCM (2) (Figure 1). In particular, the influence of the sulfur atom positions on the electronic and charge transport properties of molecules $\mathbf{1}$ and $\mathbf{2}$. These two molecules have the same atomic composition, the same anchoring groups with sulfur atoms (S) as linkers, but differ on the disposition of the latest in the terminal anchoring groups, providing molecule $\mathbf{2}$ with the $\mathrm{S}$ atoms better exposed (outer position) for anchoring to gold electrodes than molecule 1(Figure 1).

CCMoids were chosen because they represent promising building blocks for the construction of functional molecular nanocircuits; possess structural flexibility and a well-developed synthetic chemistry methodology allowing their physical and chemical properties to be tailored. Both molecules share $\square \square$-diketone group placed in the center of a seven carbon conjugated chain, that assist conductance, whose two terminal carbon atoms are bound to two terminal rings that can be chosen from a wide library of 
terminal substituents. For instance, the side groups can be easily modified to improve the electrical contact with electrodes (eg.:thiophene), and the central chelating $\beta$ diketone group allows coordination to metal ions, ${ }^{10,11}$ such as $\mathrm{Cu}^{\mathrm{II}}, \mathrm{Zn}^{\mathrm{II}}, \mathrm{Mn}^{\mathrm{II}}, \mathrm{V}^{\mathrm{IV}}$, $\mathrm{Ru}^{\mathrm{II}},{ }^{10}$ as well as lanthanides $\mathrm{Dy}{ }^{\mathrm{III}}, \mathrm{Tb}^{\mathrm{III}}, \mathrm{Eu}^{\mathrm{III}}, \mathrm{Gd}^{\mathrm{III}}$ and $\mathrm{Lu}^{\mathrm{III}} .^{11}$ Recently, an antracenebased CCMoid, called 9Accm, and a $\mathrm{Cu}^{\mathrm{II}}-9 \mathrm{Accm}$ compound have been studied in molecular break-junctions devices made of few layers of graphene (FLG). ${ }^{12}$ To our best knowledge, charge transport studies of CCMoids using gold electrodes have not been reported yet.

First, we study, in the bulk, different ways to obtain experimentally and theoretically the frontier orbitals and HOMO-LUMO band gap energies of these two curcuminoid molecules, in the gas phase, in solution and in the solid state. Generally speaking, the difference in conductance of two molecules can be predicted based on the difference of band gap energy, even though being this band near the fermi level is also important. As a first approximation, a small HOMO-LUMO gap energy is beneficial for the molecular conductance properties. However, it is known that their frontier orbital energies will change based on the hybridization of these orbital wave functions with those of the metallic leads in the electronic device. ${ }^{10 c-e}$ We have performed electrochemical studies on self-assembled monolayers of these molecules to understand how the frontier orbitals and HOMO-LUMO band gap energies can change in the molecule-surface interaction. Finally, we have performed conductance studies using a mechanically controlled break junction (MCBJ) device in the electrode-molecule-electrode configuration. We support our findings by DFT calculations.

\section{Results and Discussion}

Compounds 1 and 2, shown in Figure 1, were synthesized by a modified version of the Pabon's method. ${ }^{13}$ The structural difference between both molecules regarding the disposition of the $\mathrm{S}$ atoms is mentioned above. Such difference may influence not only their electronic and charge transport properties but also their binding abilities toward the surface of the electrode. In order to determine the difference in energy of these frontier orbitals we have performed measurements on the macroscopic scale, including electrochemical studies in solution (differential pulse voltammetry (DPV)) and UV-Vis spectra in solution and in the solid state.

Electrochemical studies in solution. Cyclic voltammetry (CV) and differential pulse voltammetry (DPV) were used to investigate the redox properties of $\mathbf{1}$ and $\mathbf{2}$ and to 
estimate values of the HOMO and LUMO energy levels of both systems. Figure 2 shows the CV and DPV experiments and the electrochemical data are summarized in Table S2. Overall, the two compounds display a similar electrochemical behavior, exhibiting a number of irreversible reductions in the -2.5 to $-1.5 \mathrm{~V}$ region and three close irreversible oxidations in the +0.5 to $+2.0 \mathrm{~V}$ range (Figures S5-S8), showing features that are similar to other thiophene species reported in the literature. ${ }^{14}$ However, a closer look at the DPV data shows that potentials for the first oxidation and reduction processes are shifted between 1and 2 (Table S2). Compound 1 presents the first oxidation and reduction processes at +0.87 and $-1.66 \mathrm{~V}$, respectively, whereas 2 displays these processes at +0.95 and $-1.80 \mathrm{~V}$ (both referred vs. $\mathrm{Fc} / \mathrm{Fc}^{+}$).

The HOMO is estimated ${ }^{15 a, b}$ from the first oxidation potential, corresponding to the ionization potential, IP (removal of one electron from the highest occupied molecular orbital) and the LUMO is deduced from the first reduction potential, correlated to the electron affinity, EA (addition of one electron to the lowest unoccupied orbital). To proceed with the calculations and to compare the experimental values with previous published data, one has to consider that the $\mathrm{Fc} / \mathrm{Fc}^{+}$couple has a potential of $4.80 \mathrm{eV}$ below the vacuum level. ${ }^{15 b, c}$ Therefore, the HOMO and LUMO energy levels ( $\mathrm{E}_{\mathrm{HOMO}}$ and $\mathrm{E}_{\mathrm{LUMO}}$ ) of both molecules can be calculated according to the following equations:

$\mathrm{E}_{\mathrm{HOMO}}=-\left(\mathrm{E}_{\text {onset(ox })}+4.8\right) \mathrm{eV}$ and

$\mathrm{E}_{\mathrm{LUMO}}=-\left(\mathrm{E}_{\text {onset(red })}+4.8\right) \mathrm{eV}$, so that

$\mathrm{E}_{\mathrm{g}}=\mathrm{E}_{\text {onset(ox) }}-\mathrm{E}_{\text {onset(red) }} \mathrm{eV}$

where $\mathrm{E}_{\text {onset(ox) }}$ and $\mathrm{E}_{\mathrm{onset}(\mathrm{red})}$ are the onsets ${ }^{15 \mathrm{~d}}$ for the oxidation and reduction potentials of 1 and 2 determined from the DPV experiments ( $\mathrm{vs.} \mathrm{Fc} / \mathrm{Fc}^{+}$).

As a result, the corresponding HOMO and LUMO energy levels are -5.53 and $-3.26 \mathrm{eV}$ for $\mathbf{1}$, and -5.58 and $-3.11 \mathrm{eV}$ for $\mathbf{2}$, respectively (Table S3). Hence, the electrochemical band gaps, $\mathbf{E}_{\mathbf{g}}{ }^{\mathbf{e c}}$, are 2.27 and $2.47 \mathrm{eV}$ respectively. Additional calculations referring the electrochemical data to $\mathrm{SCE}^{15 \mathrm{e}}$ and using the appropriated formulae ${ }^{15 \mathrm{~b}}$ provide similar values (see Table S3). These energies as well as the gap values are comparable to other conjugated systems being in the order of donor polymers and small molecules. ${ }^{14,15 \mathrm{a}-\mathrm{c}}$ For both molecules, the metal Fermi level is found to lie closer to the HOMO than to the LUMO energy levels. 
Optical Studies. The electronic absorption spectra of both molecules in the solid state (Figure S9) were used to obtain the HOMO-LUMO gap of the molecules, which are summarized in Table 1. Even though $\mathbf{1}$ and $\mathbf{2}$ show a similar shape comparing their absorbance spectra there is a reduction of the absorption area and a clear blue shift of the maxima band of approximately $20 \mathrm{~nm}$ going from system 1 to 2 (Figure S9). Such a shift is associated with the aromatic nature of the 2-thiophene and 3-thiophene groups, being the conjugation less extended over the thiophene rings inthe lastest. The assignment of that band at the $400 \mathrm{~nm}$ region is attributed to $\pi \pi^{*}$ transitions, as well as to the high-energy bands in the $200-270 \mathrm{~nm}$ range. ${ }^{16}$

Based on the absorption spectra obtained for $\mathbf{1}$ and $\mathbf{2}$, the optical band gap of the frontier orbitals $\left(E_{\mathrm{g}}{ }^{o p}\right)$ were estimated using the cutoff (onset) of the lowest absorbed energy in their respective $\mathrm{UV}$-vis spectrum. The $\mathrm{E}_{\mathrm{g}}{ }^{\mathrm{p}}$ in solid provided values of $2.20 \mathrm{eV}$ for 2thphCCM (1) and $2.45 \mathrm{eV}$ for 3-thphCCM (2), respectively.

DFT calculations in the gas phase and solution. To calculate the HOMO-LUMO gap we have run two sets of calculations: i) Based on Koopmans theorem (KT) ${ }^{17}$ Density Functional Theory calculations (DFT) in the gas and ii) DFT including the effect of solvent $\left(\mathrm{CH}_{2} \mathrm{Cl}_{2}\right)$ and De Tomasi's continuum polarizable method in order to compare with experimental measurements from UV-vis spectra.

Table 1 shows the calculated band gap energies for the molecules in the gas-phase and in solution. The HOMO and LUMO data calculated including the solvent effect show quite a good agreement to the experimental data from the UV-vis experiment in solution (Figure S9). Based on the comparison of the calculated band gap energies of both molecules, molecule 1 has smaller energies than 2. Band gap energies for both molecules obtained from solid-state optical absorption or solution electrochemistry are in agreement. All the energies obtained for $\mathbf{1}$ and $\mathbf{2}$, show the same trend, suggesting to a first approximation, that molecule $\mathbf{1}$ could conduct better.

Table 1. Comparison of band gap energies $(\mathrm{eV})$ of compound $\mathbf{1}$ and $\mathbf{2}$ in the gas, solution or solid phase.

\begin{tabular}{|l|l|l|}
\cline { 2 - 3 } \multicolumn{1}{c|}{} & $\mathbf{1}$ & $\mathbf{2}$ \\
\hline TC gas phase $\lceil\mathrm{a}]$ & 5.72 & 5.96 \\
\hline TC solution phase $\lceil\mathrm{a}]$ & 3.08 & 3.26 \\
\hline $\mathbf{E}_{\mathrm{o}}^{\mathrm{op}}(\mathrm{eV})$ solid $[\mathrm{b}]$ & 2.20 & 2.45 \\
\hline $\mathbf{E}_{\mathrm{o}}^{\mathrm{ec}}(\mathrm{eV})$ solution $\lceil\mathrm{c}]$ & 2.27 & 2.47 \\
\hline
\end{tabular}


[a] Calculated by theoretical. [b] calculated from UV-vis measurement. [c] calculated from electrochemical data.

Representation of the molecular orbitals for the HOMO and LUMO electronic states for compound $\mathbf{1}$ and $\mathbf{2}$ are presented in Figure 3, showing the typical delocalization of the charge of a conjugated molecule, using $\pi$-type orbitals along the complete structure. Two observations can be made comparing the molecular orbitals of 1 and 2: (i) molecule $\mathbf{1}$ has a reduced capacity for eventual charge transfer since the $\mathrm{S}$ atomsare less involved in the HOMO orbital, (ii) looking at the LUMO orbital, molecule 2 is less conjugated, where two carbon atoms of each thiophene ring are not participating in the conjugation of the complete structure, showing a more direct path for eventual charge transport from one sulfur atom to the other in the molecule, favoring better conductance. Therefore, depending on if the charge transport is through the HOMO or the LUMO orbitals, the conductance of both molecules could be different. Based on the proximity of the HOMO energies of both molecules, obtained from electrochemistry, with the fermi level of gold, as a first aproximation, the injection could be through the HOMO. To study how these molecular frontier orbital energies changewith the orbital mixing in two dimensions in a molecule-gold electrode interaction, we performed electrochemical studies on self-assembled monolayers (SAMs).

Electrochemical Studies on SAMs. Electrochemical studies of self-assembled monolayers (SAMs) of $\mathbf{1}$ and $\mathbf{2}$ on $\mathrm{Au}(111)$ were also carried out in order to evaluate the changes in the HOMO and LUMO energy levels. The results are summarized in Table 2. The experimental conditions used were the same as for the bulk electrochemical measurements discussed above. The formation of SAMs was confirmed through the observation of reductive desorption processes of the SAMs from the Au(111) surfaces, corroborating the chemisorption between the thiophene sulfur atoms to the gold surface. ${ }^{18}$ Cyclic voltammetry measurements were conducted for both self-assembled systems, SAM(2-thphCCM-Au(111)) for 1 and SAM(3-thphCCM-Au(111)) for 2. Two oxidation and four reduction processes are present in both SAMs, as shown in Figure 4. The redox behavior of SAM(2-thphCCM-Au(111)) was similar to SAM(3-thphCCM$\mathrm{Au}(111)$ ), and the redox processes for the oxidation and reduction in both systems are much closer than those found in solution (Figure 2). As before, differential pulse voltammetry (DPV) provided a better resolution of the redox processes. 
Table 2. Electrochemical data in $\mathrm{CH}_{2} \mathrm{Cl}_{2}$ for compounds $\mathbf{1}$ and $\mathbf{2}$ in solution and in SAMs configuration. Potentials (V) (DPV data) are referred to $\mathrm{Fc} / \mathrm{Fc}^{+} . \mathrm{E}_{\mathrm{HOMO}}$ and $\mathrm{E}_{\mathrm{LUMO}}(\mathrm{eV})$ refer to the HOMO and LUMO energy levels, $\mathrm{E}_{\mathrm{g}}{ }^{\mathrm{ec}}(\mathrm{eV})$ stands for electrochemical energy gap.

\begin{tabular}{|c|c|c|c|c|c|}
\hline & $\begin{array}{l}1^{\text {st }} \\
\text { Oxid }\end{array}$ & $\begin{array}{l}1^{\text {st }} \\
\text { Red }\end{array}$ & $\begin{array}{l}\mathbf{E}_{\mathrm{HO}} \\
\text { мO }\end{array}$ & $\begin{array}{l}\mathbf{E}_{\mathrm{LU}} \\
\text { мо }\end{array}$ & $\begin{array}{l}\mathbf{E}_{\mathbf{g}}^{\mathbf{e}} \\
\mathrm{c}\end{array}$ \\
\hline $\begin{array}{l}1 \\
\text { Sol. }\end{array}$ & +0.87 & -1.66 & $\begin{array}{l}- \\
5.53\end{array}$ & $\begin{array}{l}- \\
3.26\end{array}$ & $\begin{array}{l}2.2 \\
7\end{array}$ \\
\hline $\begin{array}{l}2 \\
\text { Sol. }\end{array}$ & +0.95 & -1.80 & $\begin{array}{l}- \\
5.58\end{array}$ & $\begin{array}{l}- \\
3.11\end{array}$ & $\begin{array}{l}2.4 \\
7\end{array}$ \\
\hline $\begin{array}{l}1 \\
\text { SAM }\end{array}$ & +0.78 & -0.33 & $\begin{array}{l}- \\
5.40\end{array}$ & $\begin{array}{l}- \\
4.65\end{array}$ & $\begin{array}{l}0.7 \\
5\end{array}$ \\
\hline $\begin{array}{l}2 \\
\text { SAM }\end{array}$ & +0.93 & -0.30 & $\begin{array}{l}- \\
5.42\end{array}$ & $\begin{array}{l}- \\
4.68\end{array}$ & $\begin{array}{l}0.7 \\
4\end{array}$ \\
\hline
\end{tabular}

SAM(2-thphCCM-Au(111)) for 1 presents the first oxidation and reduction processes at +0.78 and $-0.33 \mathrm{~V}$ respectively, and SAM(3-thphCCM-Au(111)) for 2 displays parallel redox processes at +0.93 and $-0.30 \mathrm{~V}$. The comparison of these potentials with the ones obtained for the molecules in solution, suggests that the oxidation potentials for the SAM configurations have experienced small shifts toward positive values, while the reduction potentials show pronounced shifts to less negative values.

Shifts of the redox processes for compounds anchored to the Au surface, compared to their electrochemical processes in solution, have been previously observed for thiophene alkanethiol and terthiophene-derivative SAMs on gold surface. ${ }^{19}$ Overall, the oxidation potential processes are similar in both experiments, in solution and as SAMs attached to $\mathrm{Au}$. In contrast, there is a big difference between the reduction potentials of both molecular SAMs and their corresponding molecular potentials in solution, with molecular SAMs reduction values very close to each other(-0.3 V (1) and $-0.33 \mathrm{~V}(\mathbf{2}))$. The energy gap between the HOMO and LUMO energy levels was calculated using the same methodology as introduced for the electrochemical experiments in solution (Table S4). We found that the electrochemical band gaps, e.g., for $\mathbf{1}$ and $\mathbf{2}$ when are in contact 
with the gold electrode are 0.75 and $0.74 \mathrm{eV}$, respectively. This change in the band gap energies upon binding is mainly due to the mixing of the LUMO orbitals with the orbitals of the gold electrode, since the HOMO orbitals are almost the same form both molecules. When compounds $\mathbf{1}$ and $\mathbf{2}$ are anchored to the gold surface, the reduction potencials (or the LUMO energies) causes the reduction of the band gaps energy obtaining smaller values than the ones obtained for the molecules in solution. Comparing the frontier orbital energies with the reported Fermi energy of gold electrodes $(5.1 \mathrm{eV})^{20}$ we see that the later falls in between the HOMO and LUMO energy levels of both molecules (Table 2), suggesting that this molecules may show conductance if a single molecule device is constructed. Based on the electrochemical measurements on SAMs we can conclude that the interaction with the gold electrodes reduces the LUMO energies of both molecules, ending up with a smaller and similar band gap for both molecules, therefore as a first approximation, if everything else is the same, both molecules will show similar conductances in a single-molecule device with gold electrodes.

Single-Molecule Conductance Measurements. Single-molecule conductance measurements were performed with the controllable mechanical break junction technique (MCBJ). ${ }^{21} \mathrm{~A}$ drop of the molecular solution was deposited on the device before breaking the electrode and thousands of molecular conductance traces were collected while separating these electrodes, performing a statistical investigation by building one-dimensional and two-dimensional conductance histograms. Figure 5 displays two-dimensional conductance vs. electrode displacement histograms (G versus the electrode displacement $d$ in logarithmic scale) of a MCBJ with compound 1 (Figure 5a) and 2 (Figure 5b). In these histograms, individual breaking traces have been shifted along the horizontal electrode displacement-axis to fix the rupture of the one-atom gold contact at zero. Areas of high counts represent the most typical breaking behaviour of the molecular junctions. The insets contain the histograms with all breaking traces; the main figures show the ones build up from selected traces. In the latter case, short and steep traces have been omitted so that most of the tunnelling traces in which there are no molecular signatures, are not taken into account.

The two-dimensional histograms (Figure 5) show that for compound 1, there is region of high counts between $10^{-4}$ and $10^{-5} \mathrm{G}_{0}$ and for compound 2 , there are two regions of high counts, one just above $10^{-4} \mathrm{G}_{0}$ and one just below $10^{-5} \mathrm{G}_{0}$. To extract the 
conductance values of the most probable molecular configuration, one dimensional conductance histograms have been constructed. These 1D histograms and that of a reference sample without molecules are presented Figure 6. All three panels in this figure show, just before the rupture of the gold wire, the presence of clear steps at integer values of $1 G_{0}\left(G_{0}=e^{2} / h=77 \square \mathfrak{S}\right)$, the quantum of conductance. The histograms for the two molecules yield a distribution of conductance values peaked around $3 \cdot 10^{-5}$ $\mathrm{G}_{0}$ for $\mathbf{1}$ (Figure $6 \mathrm{~b}$ ) and two conductance peaks at $3 \cdot 10^{-4} \mathrm{G}_{0}$ and $8 \cdot 10^{-6} G_{0}$ for 2 (Figure $6 c)$.

Comparison of both histograms yields a consistent picture in which molecule $\mathbf{1}$ exhibits one stable conformation with conductance plateau around $3 \cdot 10^{-5} G_{0}$, with counts concentrated for electrode displacements between 0 and $0.7 \mathrm{~nm}$, having almost no counts at higher displacements. For molecule 2, the histograms reveal a maximum around $310^{-4} G_{0}$ and a broad maximum around $8 \cdot 10^{-6} G_{0}$, with counts spread over larger displacements, with conductance counts until $1.2 \mathrm{~nm}$ electrode displacement. Figure 1 shows that the observed differences have to be related to the different positions of the sulfur atoms in the terminal thiophene rings. If we compare the distance between the sulfur atoms in both molecules, molecule $\mathbf{1}$ has the shortest distance between them and the observed conductance counts for molecule $\mathbf{2}$ at higher electrode displacement is thus consistent with the molecular structure. Moreover, the lower conductance value (Figure 6), which corresponds to a more stretched conformation of the molecule between the electrodes, is similar in both molecules, suggesting that the change in the sulfur atom position for that conformation does not affect the conductance considerably. The high conductance value seen only for molecule 2, may thenbe related to the fact that molecule 2 has the $\mathrm{S}$ atoms at a more favorable position for anchoring to the gold electrodes, being better available for charge injection. To provide more inside on these different conformations, theoretical calculations were performed on molecules $\mathbf{1}$ and $\mathbf{2}$ between gold electrodes.

DFT calculations for the electrode-molecule-electrode configuration. To compare the single-conductance measurements with theoretical calculations, we have calculated the transmission through molecules $\mathbf{1}$ and $\mathbf{2}$ using the non-equilibrium Green's function method with a density functional theory (DFT) calculation of the ground state electron density for different electrode stretching distances. We found that the exact geometry of the molecule with respect to the electrodes plays an important role in the HOMO and LUMO energy values, as well as on the transmission through the molecular junction. To 
investigate the evolution of the molecular conformation while stretching the junction, we performed DFT calculations for various electrode separations. For more details, see methods section.

In Figure 7, we present different molecular junction configurations for molecules 1 and 2 during stretching. These three configurations are marked in Figure 8a and b with arrows in the force versus $\mathrm{Au}-\mathrm{Au}$ distance plots. The initial molecular junction configuration is presented on top, while the middle and lower configuration correspond to maxima in the forces/displacement curves. The colors in Fig 8a,b are linked to the transmission curves shown in Figure 8c. These were calculated using DFT $+\Sigma$ in combination with the non-equilibrium Greens function (NEGF) formalism.

Comparing the force-stretching curves for both molecules, the following observations can be made: First, the rupture of the molecular junction, i.e, the last local maximum in the force, marked by the red arrows, occurs at $2.99 \mathrm{~nm}$ for molecule $\mathbf{1}$, while molecule 2 can be stretched up to $3.29 \mathrm{~nm}$, so essentially 2 can be stretched more than $\mathbf{1}$. This may explain the shorter conductance plateaus for molecule $\mathbf{1}$ in the experimental conductance histograms. Second, the junction evolution for the two molecules is different. Molecule 1 shows a second peak at $2.74 \mathrm{~nm}$, with an amplitude of $0.8 \mathrm{nN}$. Molecule 2, on the other hand, shows multiple peaks, located at 2.62, 2.73 and $3.04 \mathrm{~nm}$, with amplitudes of $0.9,0.9$ and $1.6 \mathrm{nN}$, respectively. The fact that the force is twice as high for the peak at $3.04 \mathrm{~nm}$ suggests a different nature of this bond compared to the others. Inspection of the different junction geometries in Figure 7 suggests the following scenarios: (i) at the point of rupture of molecule 1, the interaction is a weak van der Waals between a distant thiophene ring and the electrode, leaving only a $\mathrm{H}$ atom of the ring as the last contact with the gold electrode. No covalent S-Au bond is formed, and the molecule/electrode interaction occurs through van der Waals forces. The peak at $2.73 \mathrm{~nm}$ is also caused by van der Waals forces, with the entire thiophene rings interacting with the electrodes. (ii) In the case of molecule 2 the situation is different. At the point of rupture $(3.29 \mathrm{~nm})$ the hydrogen atom is the closest to the electrode suggesting a molecule/electrode interaction occurs through van der Waals forces. This is similar to molecule 1. At the positions 2.64 and $2.73 \mathrm{~nm}$, the thiophene rings overlap with the gold electrodes and van der Waals predominate again. At a distance of 3.04 $\mathrm{nm}$, however, the $\mathrm{S}$ atoms are closely located to the gold, indicating the formation of covalent bonds. This bond formation can be related to the higher breaking force. Upon 
further stretching, as seen also in molecule 1, the last molecule/electrode interaction is again through van der Waals forces.

This structural difference is also reflected in the transmission through the molecule while stretching, as shown in Fig. 8c. For molecule 1, when the molecular junction is formed via van der Waals interaction with the electrodes (red), the curves cluster around a conductance values of about $3 \cdot 10^{-3} G_{0}$. For molecule 2 , the conductance in the van der Waals regime (blue) is slightly lower than for molecule 1, and with a larger spread. When molecule 2 is connected via the Satoms (green), on the other hand, the conductance is about an order of magnitude larger. The conductance values obtained from DFT are higher than the ones found in the MCBJ experiments, and can therefore only be compared qualitatively. Nevertheless, the two different binding geometries of molecule 2 yield different conductance values, with an order of magnitude difference between the two.And the HOMO and LUMO energies of both molecules are similar as obtained experimentaly from the electrochemical measurements on SAMs.

\section{Conclusions}

In conclusion, the experimental data in solution and in the solid state show that the HOMO-LUMO band gap for molecule 1 has a lower energy value than for molecule 2. Theoretical calculations show the same trend. Inspection of the HOMO LUMO molecular orbitals show that both molecules have the typical delocalization of the $\pi$ type orbitals along the complete structure molecule, but due to the difference on the position of the sulfur atoms in the terminal thiophene rings, the electronic densities in the HOMO and LUMO orbitals are different. Analysis of the frontier molecular orbital electron densities suggest that if charge transport would occur through the HOMO orbitals, molecule 1 could show a reduced capacity for eventual charge transfer processes since the sulfur atom are less involved in the HOMO orbital. In the oppositecase scenario, where charge transport could occur through the LUMO energy levels of the molecules, molecule $\mathbf{2}$ shows a more direct path for eventual charge transport between both sulfur atoms, resulting in better conductance. Therefore, the energy band

gap for molecule $\mathbf{1}$ is smaller than for $\mathbf{2}$, but the electron energies of the HOMO and the LUMO orbitals may affect differently in the injected process to or from the molecule. Once the molecules are anchored on the gold surface electrodes, the band gap energies are significantly reduced, exhibiting a lowering of the LUMO orbital energies in both cases, showing that the band gap of both molecules end up almost the same. Single molecule measurements show that the conductance of molecule $\mathbf{2}$ is an order of 
magnitude higher than the conductance of molecule 1. Therefore, considering that the HOMO and LUMO energies are almost the same, we attribute this difference in conductance to the ability of molecule 2 to form covalent interaction to the nanogold electrodes, due to the more available position of the sulfur atoms. We supported our findings by DFT calculations. 


\section{Experimental Section}

Chemical Synthesis. The chemicals and solvents used were purchased from commercial sources and used without further purification, unless specially mentioned. All experiments were carried out in aerobic conditions using commercial grade solvents. Synthesis of ((1E,4Z,6E)-5-hydroxy-1,7-di(thiophen-2-yl)hepta-1,4,6-trien-3-one (2thphCCM) (1). Acetylacetone (acac) $(0.75 \mathrm{~mL}, 7 \mathrm{mmol})$ and $\mathrm{B}_{2} \mathrm{O}_{3}(0.35 \mathrm{~g}, 5 \mathrm{mmol})$ were dissolved in EtOAc. The reaction mixture was heated at $55{ }^{\circ} \mathrm{C}$ for 30 min until a white suspension was formed. Then, a solution containing 2-thiophenecarboxaldehyde $(1.3 \mathrm{~mL}, 14 \mathrm{mmol})$ and tri-tert-butyl borate $(8 \mathrm{~mL}, 28 \mathrm{mmol})$ in EtOAc was added over the reaction mixture and stirred for $3 \mathrm{~h}$. at $55{ }^{\circ} \mathrm{C}$. After cooling down for $1 \mathrm{~h}$ a solution of $n$-butylamine $(0.4 \mathrm{~mL}, 4 \mathrm{mmol})$ in EtOAc was added dropwise, and the reaction mixture was stirred at room temperature for 2 days. At this point a red precipitate was formed corresponding to the boron complex, which was filtered and suspended in water in order to break the complex. After a day the pure ligand was filtered and dried under vacuum. Yield: 79\%. IR $\left(v / \mathrm{cm}^{-1}\right)$ 3102, 1619, 1508, 1419, 1162, 966, 856, 705. ${ }^{1} \mathrm{H}-$ NMR (400 MHz, $\left.\mathrm{CDCl}_{3}\right) \delta 15.87(\mathrm{~s}, 1 \mathrm{H}), 7.77(\mathrm{~d}, J=15.5 \mathrm{~Hz}, 2 \mathrm{H}), 7.38(\mathrm{~d}, J=5,0 \mathrm{~Hz}$, 2H), 7,27 (d, $J=3,7 \mathrm{~Hz}, 2 \mathrm{H}), 7.07(\mathrm{dd}, J=5.0,3.7 \mathrm{~Hz}, 2 \mathrm{H}), 6.41(\mathrm{~d}, J=15.5 \mathrm{~Hz}, 2 \mathrm{H})$, $5.75(\mathrm{~s}, 1 \mathrm{H}) .{ }^{13} \mathrm{C}-\mathrm{NMR}\left(75 \mathrm{MHz}, \mathrm{DMSO}_{6}\right) \delta 182.59,139.91,133.29,132.13,130.12$, 128.84, 122.79, 101.62. IR $\left(\mathrm{v} / \mathrm{cm}^{-1}\right)$ 3102, 1619, 1508, 1419, 1162, 966, 856, 705. Elemental analysis calculated for 2-thphCCM $0.5 \mathrm{H}_{2} \mathrm{O}(\%)$ : $\mathrm{C} 60.8, \mathrm{H}$ 4.01, S 21.6; found: C 60.8, H 4.18, S 21.6. ESI-MS: m/z: 287[M-H]'.

Synthesis of ((1E,4Z,6E)-5-hydroxy-1,7-di(thiophen-3-yl)hepta-1,4,6-trien-3-one) (3thphCCM) (2). Acetylacetone (acac) $(0.75 \mathrm{~mL}, 7 \mathrm{mmol})$ and $\mathrm{B}_{2} \mathrm{O}_{3}(0.35 \mathrm{~g}, 5 \mathrm{mmol})$ were dissolved in EtOAc. The reaction mixture was heated at $55^{\circ} \mathrm{C}$ for $30 \mathrm{~min}$ until a white suspension was formed. Then, a solution containing 3-thiophenecarboxaldehyde $(1.3 \mathrm{~mL}, 14 \mathrm{mmol})$ and tri-tert-butyl borate $(8 \mathrm{~mL}, 28 \mathrm{mmol})$ of in EtOAc was added over the reaction mixture, and stirred for $3 \mathrm{~h}$. at $55{ }^{\circ} \mathrm{C}$. After cooling down for $1 \mathrm{~h}$ a solution of $n$-butylamine $(0.4 \mathrm{~mL}, 4 \mathrm{mmol})$ of EtOAc was added dropwise, and stirred at room temperature for 2 days. At this point an orange precipitate was formed, which was filtered and suspended in water for a day in order to break the boron complex. The final ligand was filtered and dried under vaccum. Yield: 69\%. IR $\left(v / \mathrm{cm}^{-1}\right) 3419,3091$, 1623, 1575, 1506, 1417, 1137, 968, 867, 794, 723, 611, 474. ${ }^{1} \mathrm{H}-\mathrm{NMR}$ (400 MHz, 
$\left.\mathrm{CDCl}_{3}\right): \delta 7.65(\mathrm{~d}, J=15,8 \mathrm{~Hz}, 2 \mathrm{H}), 7.51(\mathrm{~d}, J=3.7 \mathrm{~Hz}, 2 \mathrm{H}), 7.38-7.30(\mathrm{~m}, 4 \mathrm{H}), 6.44$ $(\mathrm{d}, J=15.7 \mathrm{~Hz}, 2 \mathrm{H}), 5.79(\mathrm{~s}, 1 \mathrm{H}) .{ }^{13} \mathrm{C}-\mathrm{NMR}\left(75 \mathrm{MHz}, \mathrm{DMSO}-\mathrm{d}_{6}\right): \delta 183.44,138.14$, 134.33, 129.67, 127.94, 125.70, 123.86, 101.42.IR ( $\left./ \mathrm{cm}^{-1}\right) 3419,3091,1623,1575$, 1506, 1417, 1137, 968, 867, 794, 723, 611, 474. Elemental analysis calculated for 3thphCCM·1.2 $\mathrm{H}_{2} \mathrm{O}(\%)$ : C 58.3, H 4.37, S 20.8; found C 58.1, H 4.17 S 20.9. ESI-MS: m/z: 287[M-H]', 575 [2M-H]'.

Physical Measurements. C, $\mathrm{H}$ and $\mathrm{N}$ analyses were performed with a Pekin-Elmer II Series CHNS/O Analyzer 2400 at the Servei de Microanàlisis del Consell Superior d'Investigació Científiques (CSIC), Barcelona. ${ }^{1} \mathrm{H}$ NMR and ${ }^{13} \mathrm{C}$ NMR spectra was recorded on a Bruker Avance-400 spectrometer.The ESI mass spectra were performed with a spectrometer LC/MSD-TOF (Agilent Technologies) with double nebulizer source. Infrared spectra $\left(4000-400 \mathrm{~cm}^{-1}\right)$ were recorded from $\mathrm{KBr}$ pellets on a Bruker Vector 22 spectrophotometer. Solution UV-Vis absorption spectra were recorded using a UV-visible Perkin-Elmer (Lambda II) spectrophotometer. Solid UV-Vis absorption spectra were recorded using diffuse reflectance sphere DRA-2500 accessory in a UVVis-NIR Varian Cary 5000 spectrophotometer. Only distilled solvents $\left(\mathrm{CH}_{2} \mathrm{Cl}_{2}\right)$ were employed and concentrations of compound 1 and 2 were $10 \cdot 10^{-6} \mathrm{M}$.

Electrochemistry. Cyclic Voltammograms (CV) and Differential Pulse Voltammograms in solution were recorded with a potenciostat SP-150 (BioLogic) modulated with the program EC-Lab V10.02, at the Universitat de Barcelona. A standard three-electrode assembly (glassy carbon working together with auxiliary and reference platinum electrodes) with $0.1 \mathrm{mM} \mathrm{NBu}_{4} \mathrm{PF}_{6}$ as supporting electrolyte. No IR compensation was employed. Quoted potentials are vs the ferrocene/ferrocenium couple, used as an internal standard. The scan rates for cyclic voltammetry (CV) and differential pulse voltammetry (DPV) were 50 and 50-100 mV/ s, respectively. Distilled solvents were employed, and the concentrations of the complexes were approximately 1 $\mathrm{mM}$.

Computational Details. Theoretical analysis was performed with Gaussian code, ${ }^{22}$ using the 03 and 09 versions. It considers optimization of the ground state geometry of 2-thphCCM (1) and 3-thphCCM (2) using density functional theory (DFT) methodology with the Becke, Lee, Yang and Parr B3LYP hybrid functional for exchange and correlation effects and the $6-311 \mathrm{G}+(\mathrm{d}, \mathrm{p})$ basis set. A two-step procedure previously used ${ }^{23}$ is implemented to resolve the geometry and energy of the ground state for the several hypothetic conformers of the 2-thphCCM (1) and 3-thphCCM (2) 
compounds, both in the gas phase and in solvent, considering the Tomasi's Polarized Continuum Model (PCM) to account for the effect of the dichloromethane solvent used in UV-Vis experimental spectra. The vertical $S_{0} \rightarrow S_{n}(n=1$ to 5) singlet-singlet transitions corresponding to absorption spectra of each of the 2-thphCCM and 3thphCCM oligomers were resolved by time-dependent DFT (TD-DFT/B3LYP/6$311 \mathrm{G}+(\mathrm{d}, \mathrm{p}))$ calculations ${ }^{24}$ including solvent effect. Electronic densities of the HOMO and LUMO states were also obtained. Luminescence spectra were calculated optimizing the first singlet excited state structure and studying the vertical transition.

The DFT stretching calculations were performed using the ADF software package. ${ }^{25}$ The dispersion-corrected GGA PBE exchange-correlation functional and the triple- $\zeta$ plus polarization (TZP), Slater-type orbital local basis-set were used. All electrons were taken into account, expect for the gold where a large frozen core was used. To account for relativistic effects in the electrodes, the zeroth order regular approximation (ZORA) to the Dirac equation was used. Geometries were converged to energy changes of less than $10^{-3}$ hartree, energy gradients of less than $1 \cdot 10^{-3}$ hartree/ $\AA$ maximum and $6.7 \cdot 10^{-4}$ hartree/Å RMS. The electrodes were modeled as two gold pyramids terminated with (111) surfaces. Each electrode consists of 5 layers, as shown in Figure 7. The initial electrode separation is $2.54 \mathrm{~nm}$, as shown in the left panel. The electrode separation is determined from the distance between the outer gold layers, center-to-center. The calculations were performed as follows. First, the molecular geometry was relaxed for the electrode while keeping the coordinates of the outer three gold layers fixed. Only the inner two layers were allowed to relax. After convergence, electrodes were pulled outwards, each with a displacement of $0.02 \AA$, and the geometry was optimized again. This process was repeated until the $\mathrm{Au}-\mathrm{Au}$ distance reached $4.40 \mathrm{~nm}$. Transmission were performed.

To correct for well-known correlation errors upon addition/removal of a charge on the molecule, the DFT $+\Sigma$ method was employed. ${ }^{26}$ The $\Sigma$ correction consists of two parts. First, a correction to the ionisation potential and electron affinity is calculated based on gas phase calculations for the molecule with $-1,0$ and +1 electron. Second, imagecharge effects were calculated for the different charge states (also in gas-phase) using the Hirschfeld atomic charge distribution between two parallel plates. The image planes were set at a distance of 1.5 Angstrom away from the sulfur atoms. Both corrections were implemented as a scissor operator. To compute the transmission, the outer two gold layers were coupled to wide-band limit electrodes. ${ }^{27}$ 


\section{Electrochemistry measurements on self-assembled monolayer of compound 1 and}

2 on gold electrodes. Electrochemical experiments were conducted using dry $\mathrm{CH}_{2} \mathrm{Cl}_{2}$ $0.1 \mathrm{M}\left(\mathrm{NBu}_{4}\right)\left(\mathrm{PF}_{6}\right)$ solutions. Before each measurement, the organic solution was purged with ultrapure $\mathrm{N}_{2}$ gas for about $10 \mathrm{~min}$, prior to each measurement. The working electrode was a thin vapor deposited $\mathrm{Au}$ film deposited on glass $(12 \times 12 \mathrm{~mm}$ slides purchased from Arrandee, Germany). The reference electrode was a platinum wire, and other platinum wire served as the counter electrode. Final redox potentials were referred to the ferrocene/ferrocenium $\left(\mathrm{Fc} / \mathrm{Fc}^{+}\right)$couple. Gold slides (working electrode) were annealed using a $\mathrm{H}_{2}$ flame, to obtain preferential $\mathrm{Au}(111)$ orientation. After annealing, the $\mathrm{Au}(111)$ slides were placed in an ethanol $50 \mu \mathrm{M}$ solution containing 2-thphCCM or 3-thphCCM. The time required to obtain the SAMs was $24 \mathrm{~h}$. After this period, the electrodes were further rinsed with ethanol for $10 \mathrm{~min}$. and dried using a nitrogen flow. The electrodes modified with SAMs were characterized using cyclic voltammetry (scan rate of $50 \mathrm{mVs}^{-1}$ ) and differential pulse voltammetry (scan rate of $20 \mathrm{mV} \mathrm{s}^{-1}$, pulse amplitude of $25 \mathrm{mV}$ and a pulse width of $50 \mathrm{~ms}$ ).

Single-Molecule Conductance Measurements. The transport properties of singlemolecule junctions were studied using lithographic mechanically controllable break junctions (MCBJs) in air at room temperature. Details concerning the experimental procedures are given elsewhere. ${ }^{50}$ The layout of an MCBJ device in a three-point bending mechanism is shown in Figure 9. The sample is bent by a pushing rod, whose vertical movement is controlled by a stepper motor in combination with a piezo stack. The moving rate of the electrodes was 0.6 to $6 \mathrm{~nm} \mathrm{~s}^{-1}$.

Prior to molecular deposition, we first characterized the gold electrodes at room temperature; we measured the current passing through the MCBJ device at a fixed bias voltage of $0.1 \mathrm{~V}$ applied across the electrodes, while driving up and down the pushing rod to mechanically break and form the contact. The current was measured with a battery-powered logarithmic amplifier capable of detecting currents over a range of nine orders of magnitude. To obtain statistically significant data, sets up to 5000 consecutive breaking traces from individual junctions were analyzed numerically without any data selection.

After the initial characterization of the clean junction, deposition of the molecules was performed in situ by pipetting a $1 \mu \mathrm{L}$ droplet of the target molecule in solution on the gold electrodes. The solution was prepared just before the experiment; $0.5 \mathrm{mMol}$ of the 
target molecule were dissolved in dichloromethane. After the deposition, we continued to monitor the conductance while breaking and reforming the gold contacts. 


\section{Acknowledgements}

This work has been founded by the FONDECYT REGULAR grants 1110206,1140770 and 1140199, PAI-CONICYT 79150041, Conicyt PFCHA 21140734, ANILLO project Act 1117, Millenium Project RC120001, the Dutch funding agencies FOM and NWO/OCW, by the EU through a RISE (DAFNEOX) project, SEP-210165479by the MICINN of Spain (projects CTQ2012-32247 and MAT2013-47869-C4-2-P). N. A.-A. and R. D.-T. also acknowledges financial support from the MINECO through the "Severo Ochoa" Programme for Centres of Excellence in R\&D (SEV- 2015-0496)

Keywords: curcumin derivatives - curcuminoid - HOMO-LUMO band gap energies • differential pulse voltammetry $\bullet$ self-assembled monolayer, SAM • gold electrodes • mechanically controlled break junction $(\mathrm{MCBJ}) \cdot \mathrm{DFT}$ calculations 


\section{References}

[1]a) M. Ratner,Nature Nanotechnology 2013,8, 378-381; b) M. Tsutsui, M. Taniguchi, Sensors 2012, 12, 7259-7298.

[2]a) L. Sun, Y. A. Diaz-Fernandez, T. A. Gschneidtner, F. Westerlund, S. Lara-Avila, K. Moth-Poulsen, Chem. Soc. Rev. 2014, 43, 7378-7411; b) S. V. Aradhya, L. Venkataraman, Nature Nanotechnology 2013, 8, 399-410.

[3]a) N. J. Tao, Nature Nanotechnology 2006, 1, 173-181; b) P. Moreno-García, M. Gulcur, D. Z. Manrique, T. Pope, W. Hong, V. Kaliginedi, C. Huang, A. S. Batsanov, M. R. Bryce, C. Lambert, T. Wandlowski, J. Am. Chem. Soc. 2013, 135, 12228-12240;

c) M. Kamenetska, M. Koentopp, A. C. Whalley, Y. S. Park, M. L. Steigerwald, C. Nuckolls, M. S. Hybertsen, L. Venkataraman, Phys. Rev. Lett. 2009, 102, 126803.

[4]M. L. Perrin, R. Frisenda, M. Koole, J. S. Seldenthuis, J. A. Celis Gil, H. Valkenier, J. C. Hummelen, N. Renaud, F. C. Grozema, J. M. Thijssen, D. Dulić, H. S. J. van der Zant, Nature Nanotechnology 2014, 9, 830-834.

[5]a) L. Venkataraman, J. E. Klare, C. Nuckolls, M. S. Hybertsen, M. L. Steigerwald, Nature 2006, 442, 904-907; b) B. Capozzi, E. J. Dell, T. C. Berkelbach, D. R. Reichman, L. Venkataraman, L. M. Campos, J. Am. Chem. Soc. 2014, 136, 1048610492.

[6]E. Leary, A. La Rosa, M. T. Gonzalez, G. Rubio-Bollinger, N. Agraït, N. Martin, Chem. Soc. Rev. 2015, 44, 920-942.

[7]A. Coskun, J. M. Spruell, G. Barin, W. R. Dichtel, A. H. Flood, Y. Y. Botros, J. F. Stoddart, Chem. Soc. Rev. 2012, 41, 4827-4859.

[8]a) F. Chen, X. Li, J. Hihath, Z. Huang, N. Tao, J. Am. Chem. Soc. 2006, 128, 1587415881; b) M. Tsutsui, M. Taniguchi, T. Kawai, J. Am. Chem. Soc. 2009, 131, 1055210556; c) J. Ponce, C. R. Arroyo, S. Tatay, R. Frisenda, P. Gaviña, D. Aravena, E. Ruiz, H. S. J. van der Zant, E. Coronado, J. Am. Chem. Soc. 2014, 136, 8314-8322; d) V. Kaliginedi, A. V. Rudnev, P. Moreno-García, M. Baghernejad, C. Huang, W. Hong, T. Wandlowski, Phys. Chem. Chem. Phys. 2014, 16, 23529-23539; e) Z. Li, M. Smeu, M. A. Ratner, E. Borguet, J. Phys. Chem. C 2013, 117, 14890-14898; f) Y. S. Park, A. C. Whalley, M. Kamenetska, M. L. Steigerwald, M. S. Hybertsen, C. Nuckolls, L. Venkataraman, J. Am. Chem. Soc. 2007, 129, 15768-15769.

[9]Y. Ie, T. Hirose, H. Nakamura, M. Kiguchi, N. Takagi, M. Kawai, Y. Aso, J. Am. Chem. Soc. 2011, 133, 3014-3022. 
[10]a) N. Aliaga-Alcalde, L. Rodriguez, M. Ferbinteanu, P. Hofer, T. Weyhermuller, Inorg. Chem. 2012, 51, 864-873; b) N. Aliaga-Alcalde, P. Marques-Gallego, M. Kraaijkamp, C. Herranz-Lancho, H. den Dulk, H. Gorner, O. Roubeau, S. J. Teat, T. Weyhermuller, J. Reedijk, Inorg. Chem. 2010, 49, 9655-9663; c) F. Kuhlwein, K. Polborn, W. Z. Beck, Anorg. Allg. Chem. 1997, 623, 1211-1219; d) K. Krishnankutty, V. D. John, Synth. React. Inorg. Met.-Org. Chem. 2003, 33, 343-358; e) M. Menelaou, T. Weyhermuller, M. Soler, N. Aliaga-Alcalde, Polyhedron 2013, 52, 398-405; f) B. Banik, K. Somyajit, G. Nagaraju, A. R. Chakravarty, Dalton Trans. 2014, 43, 1335813369; g) X. Lei, W. Su, P. Li, Q. Xiao, S. Huang, Q. Qian, C. Huang, D. Qin, H. Lan, Polyhedron, 2014, 81, 614-618; h) B. Balaji, B. Balakrishnan, S. Perumalla, A. A. Karande, A. R. Chakravarty, Eur. J. Med. Chem. 2014, 85, 458-467.

[11]a) M. Menelaou, F. Ouharrou, L. Rodriguez, O. Roubeau, S. J. Teat, N. AliagaAlcalde, Chem. Eur. J. 2012, 18, 11545-11549; b) Y. Mawani, C. J. Orvig, Inorg. Biochem. 2014, 132, 52-58.

[12] F. Prins, A. Barreiro, J. W. Ruitenberg, J. S. Seldentuis, N. Aliaga-Alcalde, L. M. K. Vandersypen, H. S. J. van der Zant, Nano Letters, 2011, 11, 4607-4611.

[13]a) H. J. J. Pabon, Recl. Trav. Chim. Pays-Bas 1964, 83, 379-386; b) U. Pedersen, P. B. Rasmussen, S.-O. Lawesson, Liebigs Annalen der Chemie. 1985, 1985, 1557-1569. [14]a) D. Liu, C. Gu, M. Xiao, M. Qiu, M. Sun, R. Yang, Polym. Chem. 2015, 6, 33983406; b) Q. Fan, Y. Liu, M. Xiao, H. Tan, Y. Wang, W. Su, D. Yu, R. Yang, W. Zhu, Org. Electron. 2014, 15, 3375-3383; c) N. Atilgan, F. Algi, A. M. Önall, A. Cihaner, Tetrahedron 2009, 65, 5776-5781; d) C. -Y. Yu, C. -P. Chen, S. -H. Chan, G. -W. Hwang, C. Ting, Chem. Mater. 2009, 21, 3262-3269.

[15]a) A. P. Kulkami, C. J. Tonzola, A. Babel, S. A. Jenekhe, Chem. Mater. 2004, 16, 4556-4573; b) J. Pommerehne, H. Westweber, W. Guss, R. F. Mahrt, H. Bässler, M. Porsch, J. Daub, Adv. Mater. 1995, 7, 551-554; d) P. I. Djurovich, E. I. Mayo, S. R. Forrest, M. E. Thompson, Org. Electron. 2009, 10, 515-520. e) The onset potentials are determined from the intersection of the tangents between the base line and the signal current. f) N. Connelly, W. E. Geiger, Chem. Rev. 1996, 96, 877-910.

[16]a) F. Zsila. Z. Bikádi, M. Simonyi, Biochem. Biophys. Res. Commun. 2003, 301, 776-782; b) Priyadarsini, K. I. J. Photochem. Photobiol. C 2009, 10, 81-95.

[17] a) T. Koopmans, Physica, 1934, 1, 104-113; b) O. Gritsenko, E. J. Baerends, Can. J. Chem. 2009, 87, 1383-1391. 
[18]I. Ponce, J. F. Silva, R. Oñate, M. Caroli, M. A. Paez, J. H. Zagal, J. Pavez, J. Phys. Chem. C 2012, 116, 15329-15341; b) J. Noh, E. Ito, T. Araki, M. Hara, Surf. Sci. 2003, 532, 1116-1120.

[19]T. Ikeda, Y. Nagata, Y. Zheng, D. Liu, H. -J. Butt, M. Shimoda, Langmuir, 2014, 30, 1536-1542.

[20]C. B. George, M. A. Ratner, J. B. Lambert, J. Phys. Chem. A 2009, 113, 38763880 .

[21]C. A. Martin, D. Ding, H. S. J. van der Zant, J. M. van Ruitenbeek, New J. Phys. 2008, 10, 065008-065026.

[22]Gaussian 09, Revision A. 01, M. J. Frisch, G. W. Trucks, H. B. Schlegel, G. E. Scuseria, M. A. Robb, J. R. Cheeseman, G. Scalmani, V. Barone, B. Mennucci, G. A. Petersson, H. Nakatsuji, M. Caricato, X. Li, H. P. Hratchian,A. F. Izmaylov, J. Bloino, G. Zheng, J. L. Sonnenberg, M. Hada, M. Ehara, K. Toyota, R. Fukuda, J. Hasegawa, M. Ishida, T. Nakajima,Y. Honda, O. Kitao, H. Nakai, T. Vreven, J. A. Montgomery, Jr.,J. E. Peralta, F. Ogliaro, M. Bearpark, J. J. Heyd, E. Brothers,K. N. Kudin, V. N. Staroverov, R. Kobayashi, J. Normand, K. Raghavachari, A. Rendell, J. C. Burant, S. S. Iyengar, J. Tomasi, M. Cossi, N. Rega, J. M. Millam, M. Klene, J. E. Knox, J. B. Cross,V. Bakken, C. Adamo, J. Jaramillo, R. Gomperts, R. E. Stratmann,O. Yazyev, A. J. Austin, R. Cammi, C. Pomelli, J. W. Ochterski, R. L. Martin, K. Morokuma, V. G. Zakrzewski, G. A. Voth,P. Salvador, J. J. Dannenberg, S. Dapprich, A. D. Daniels, O.

Farkas, J. B. Foresman, J. V. Ortiz, J. Cioslowski, and D. J. Fox, Gaussian, Inc., Wallingford CT, 2009.

[23]F. Martínez, G. Neculqueo, S. O. Vásquez, R. Letelier, M. T. Garland, A. Ibañez, J. C. Bernede, J. Mol. Struct. 2010, 973, 56-61.

[24]G. Neculqueo, V. Rojas-Fuentes, A. Lopez, R. Matute, S. O. Vásquez F. Martínez, Struct. Chem. 2012, 23, 1751-1760.

[25]a) G. te Velde, F. M. Bickelhaupt, S. J. A. van Gisbergen, C. Fonseca Guerra, E. J. Baerends, J. G. Snijders, T. Ziegler, J. Comput. Chem., 2001, 22, 931-967; b) C. Fonseca Guerra, J. G. Snijders, G. te Velde, E. J. Baerends, Theor. Chem. Acc. 1998, 99, 391-403

[26]S. Y. Quek, L. Venkataraman, H. J. Choi, S. G. Louie, M. S. Hybertsen, J. B. Neaton, Nano Lett. 2007, 7, 3477-3482.

[27]C. J. O. Verzijl, J. S. Seldenthuis, J. M. Thijssen, J. Chem. Phys. 2013, 138, 094102. 
<smiles>O=C(/C=C(O)/C=C/c1cccs1)/C=C/c1cccs1</smiles>

2-thphCCM

(1)

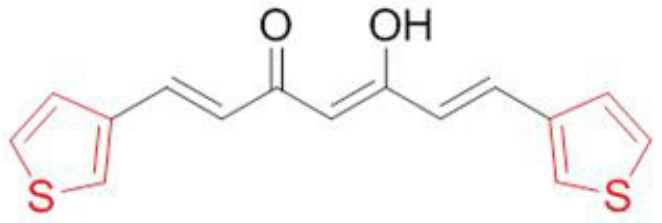

3-thphCCM

(2)

Figure 1. Thiophene-curcuminoid molecules, 2-thphCCM (1) and 3-thphCCM (2). 


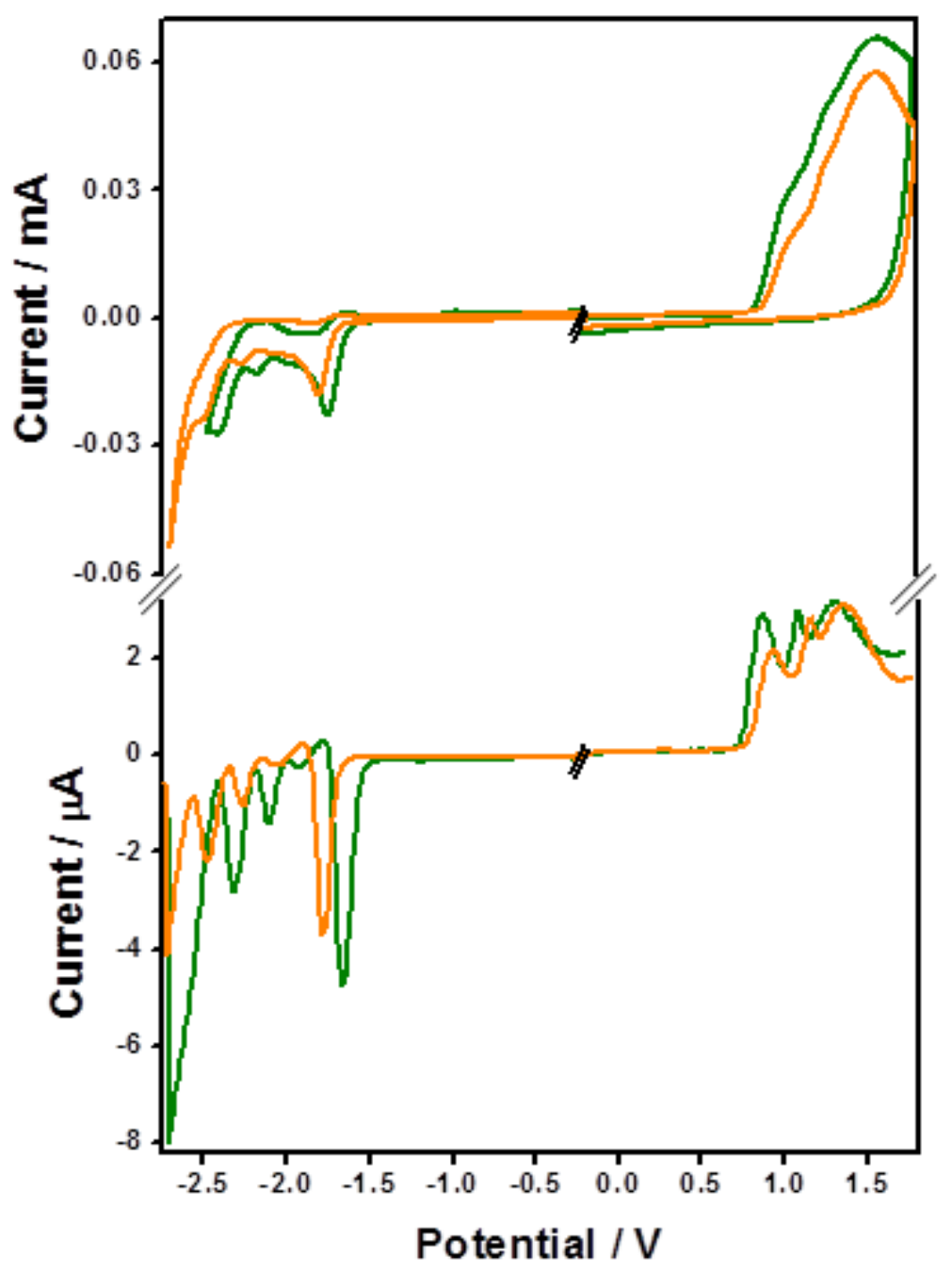

Figure 2. Cyclic voltammograms (CV) (top) and differential pulse voltammograms (DPV) (bottom) of $\mathbf{1}$ (green) and $\mathbf{2}$ (orange). Measurements were conducted in dryCH $\mathrm{Cl}_{2} \mathrm{Cl}_{2}$ under $\mathrm{N}_{2}$, containing $0.1 \mathrm{M} \mathrm{TBA}\left(\mathrm{PF}_{6}\right)$ as supporting electrolyte. Potentials vs. $\mathrm{Fc} / \mathrm{Fc}^{+}$. 
(a)
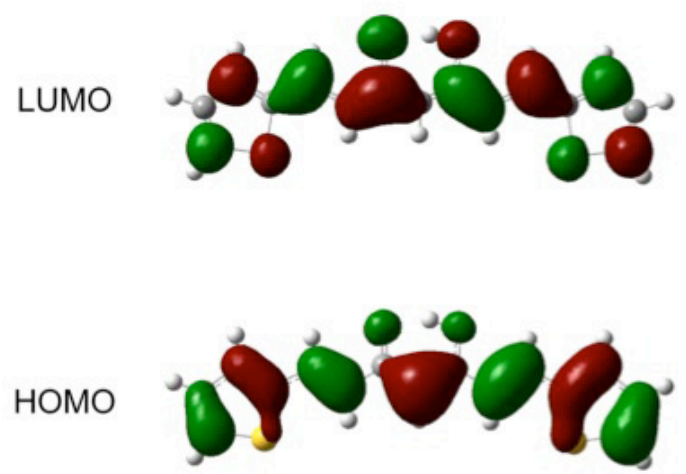

(b)
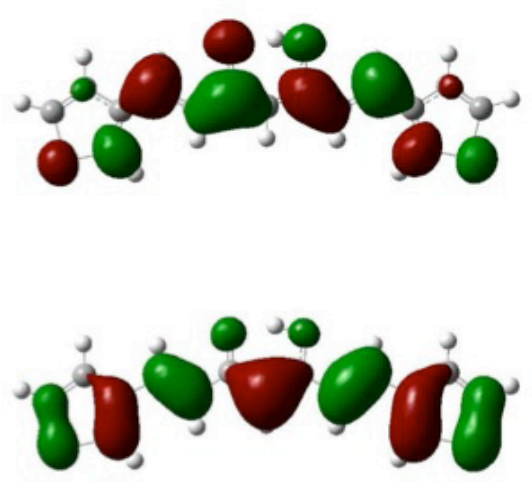

Figure 3. Molecular orbitals of a) 2-thphCCM (1) and b) 3-thphCCM (2). 


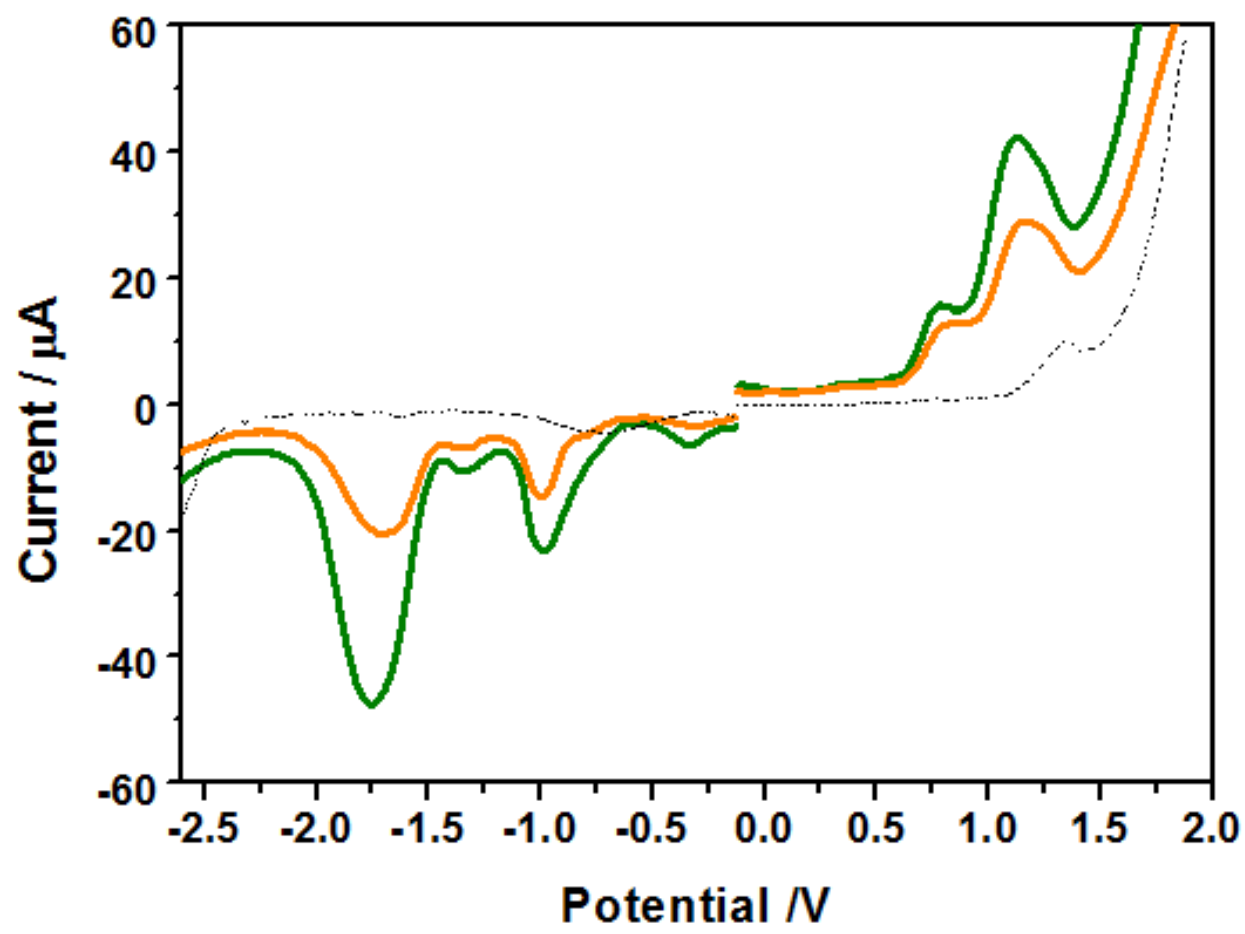

Figure 4. Differential pulse voltammograms (DPV) for Au(111) modified with SAMs of 1 (Green line) and 2 (orange line). The black dotted line represents $\mathrm{Au}(111)$ without molecules. Measurements were conducted in $\operatorname{dryCH}_{2} \mathrm{Cl}_{2}$ under $\mathrm{N}_{2}$, containing $0.1 \mathrm{M}$ $\mathrm{TBA}\left(\mathrm{PF}_{6}\right)$ as supporting electrolyte. Potentials were referred vs. $\mathrm{Fc} / \mathrm{Fc}^{+}$. 


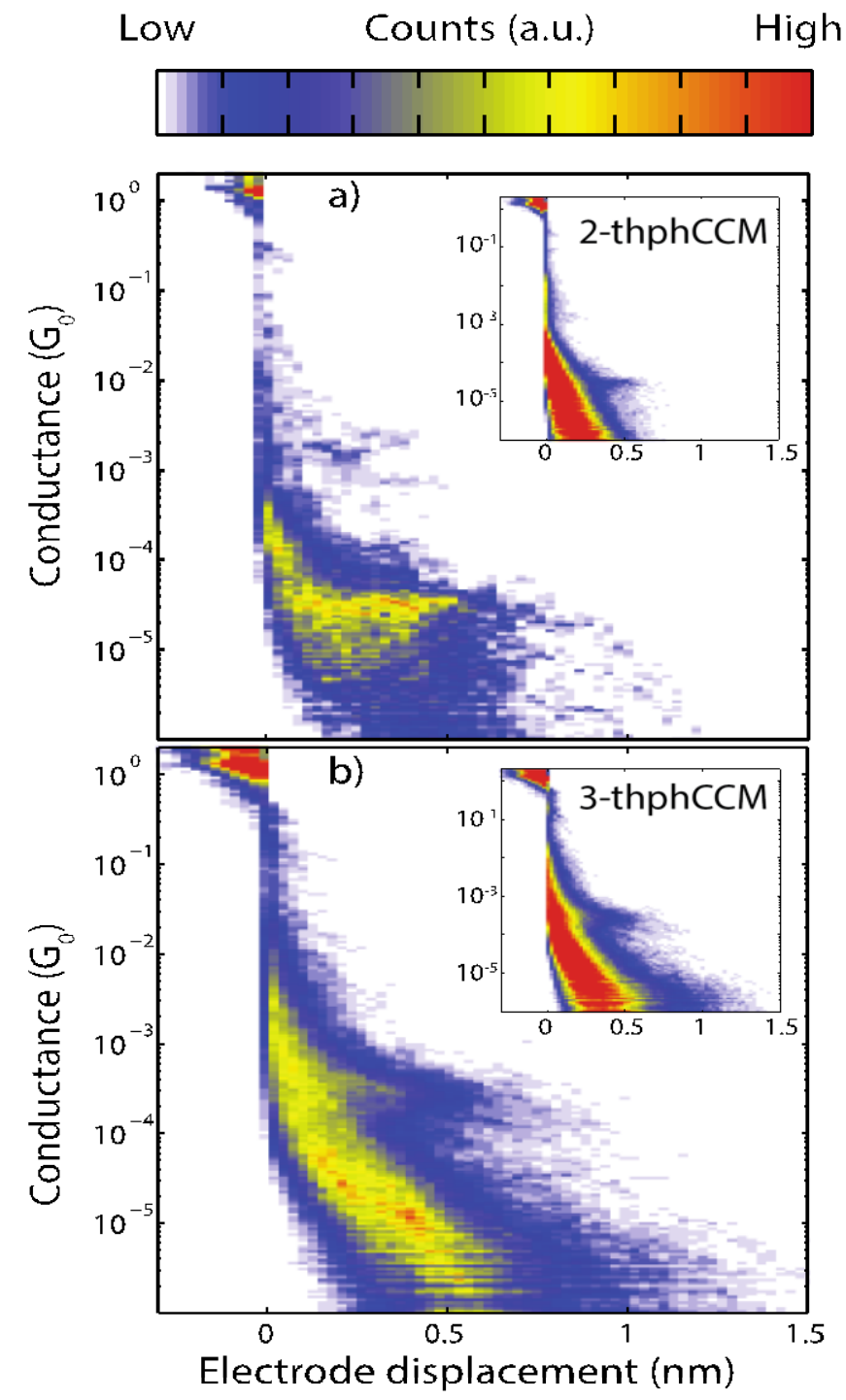

Figure 5. Conductance vs. electrode displacement two-dimensional histogram constructed with a) 171 traces of molecule 1 and b) 1299 traces of molecule 2 . The selected traces were the ones where the distance between the point at which the trace drops below $1 \mathrm{G}_{0}$ and the last point where the conductance is larger than $10^{-5} \mathrm{G}_{0}$ is longer than $0.4 \mathrm{~nm}$. The insets display the histograms without data selection constructed using 5000 traces. 


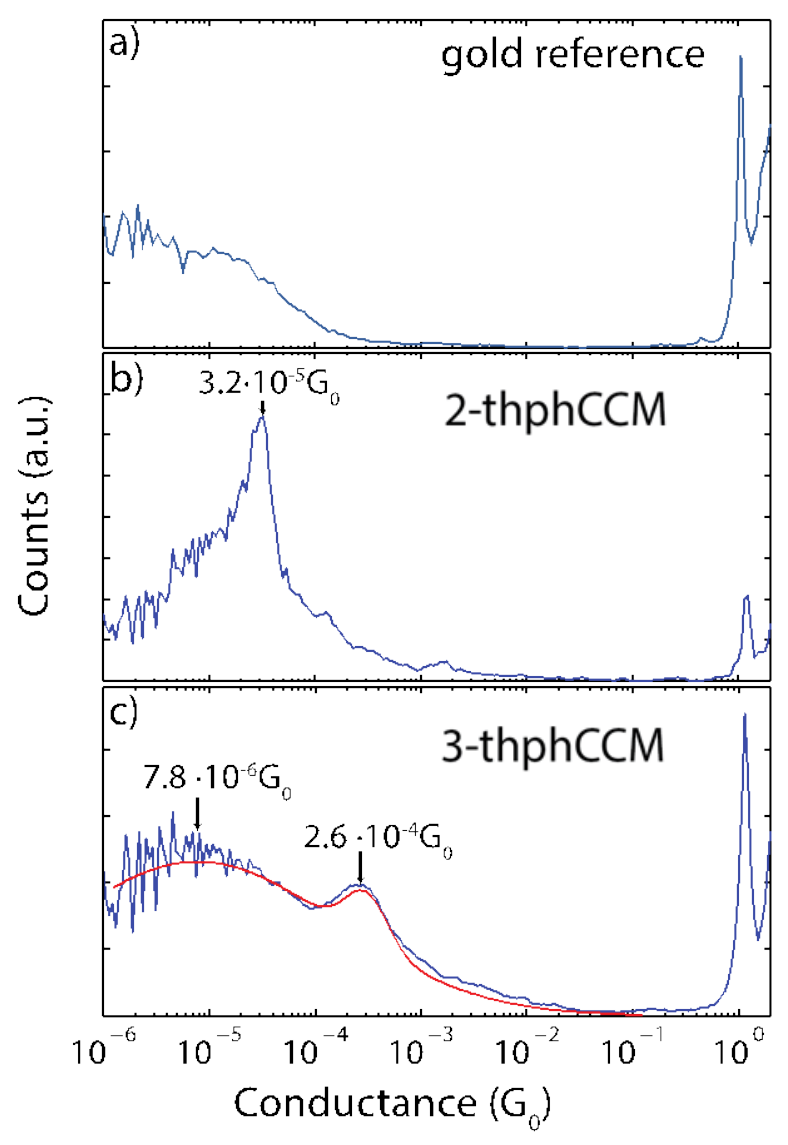

Figure 6. Logarithmically binning one-dimensional conductance histograms of a) a clean gold reference sample, b) selected traces of Figure 5 of 2-thphCCM (1) and c) 3thphCCM (2). The red solid line (lower panel) corresponds to a lognormal fitting of the two conductance peaks. 
2-thphCCM
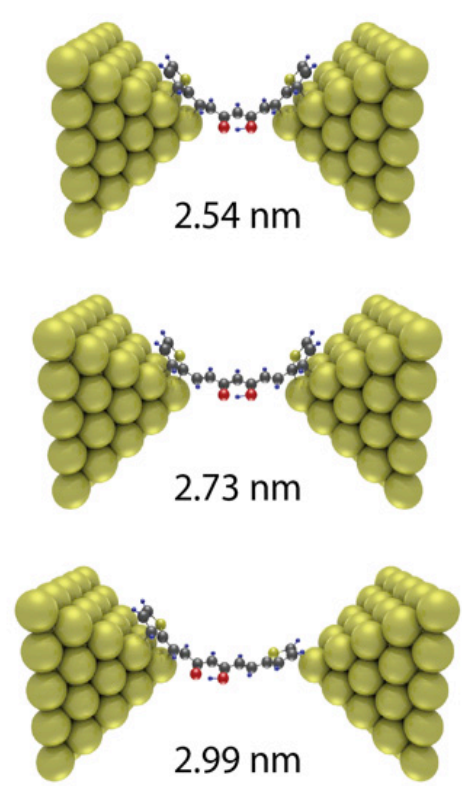

3-thphCCM
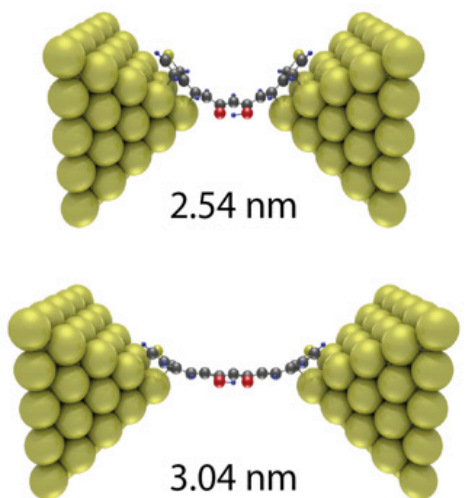

$3.04 \mathrm{~nm}$

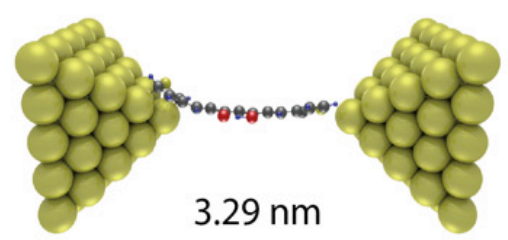

Figure 7. DFT calculations of the different molecular junction configurations (top) initial molecular junction configuration, (middle) the configuration at an intermediate stretch and (bottom) the configuration at the point of maximum stretching (bottom) for molecules $\mathbf{1}$ and $\mathbf{2}$. 

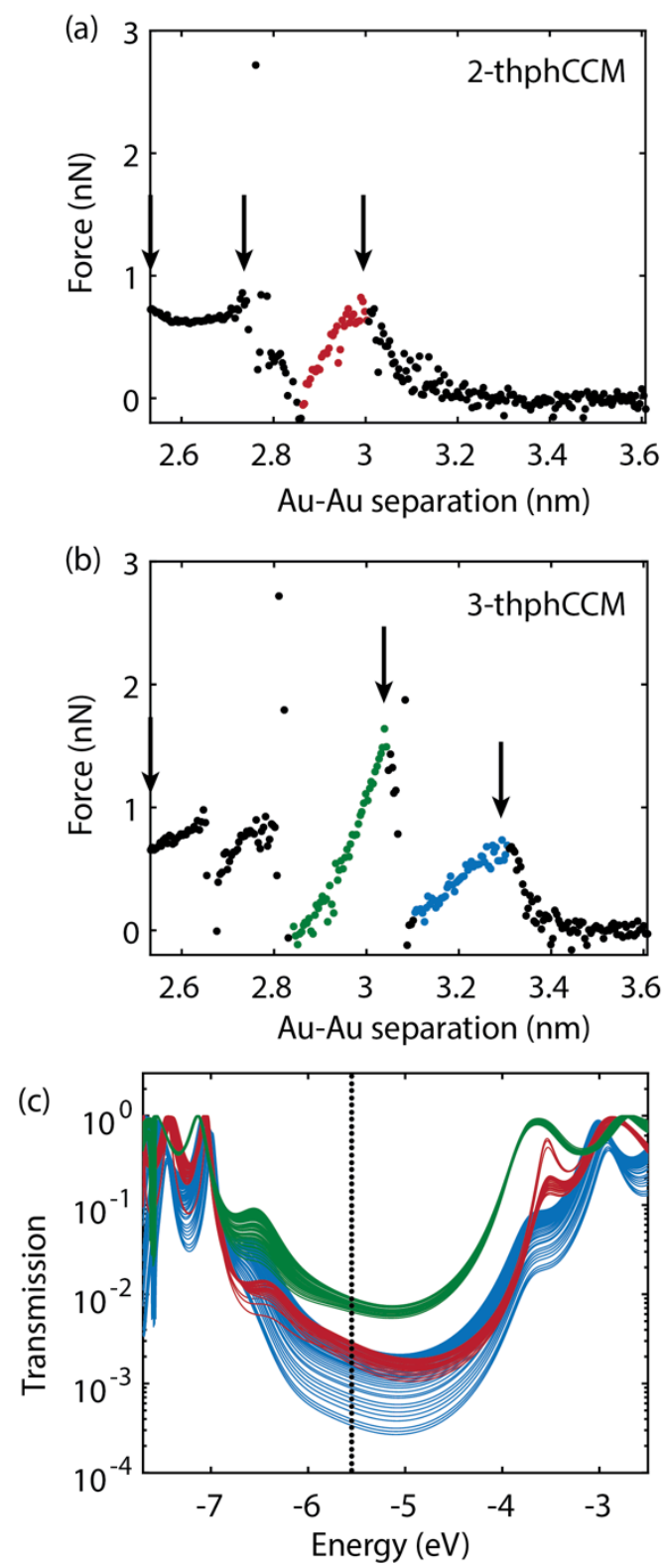

Figure 8.Calculated forces versus $\mathrm{Au}-\mathrm{Au}$ distance for the different calculated configurations for molecule 1 (a) and molecule 2 (b). c) Comparison of the calculated orbital energies for the molecules $\mathbf{1}$ and $\mathbf{2}$ (colours are related to a and b). The vertical dotted line indicates the position of the Fermi energy. 
(a)
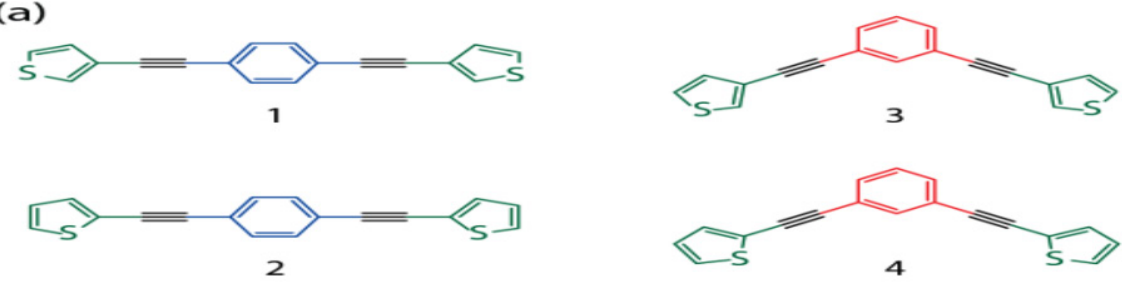

(b)

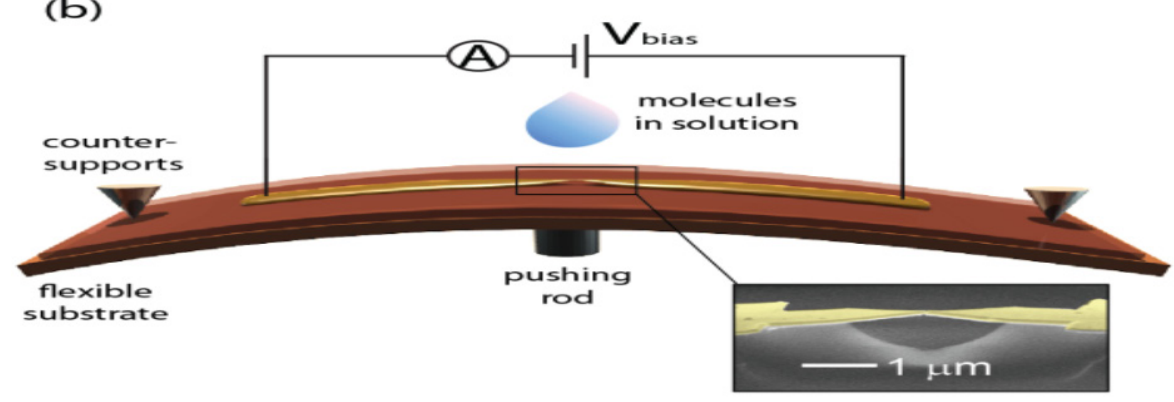

Figure 9. Lay-out of a mechanically controlled break-junction (MCBJ) setup. Inset: scanning electron micrograph of a MCBJ device. 